\title{
Pengungkapan Identitas Diri Melalui Komunikasi Non Verbal Artifaktual Pada Komunitas Crossdress Cosplay Jepang
}

\author{
Fasa Bikati Sabka, Yugih Setyanto, Septia Winduwati \\ fasa,915150083@stu.untar.ac.id,yugihs@fikom.untar.ac.id, Septiaw@fikom.untar.ac.id \\ Fakultas Ilmu Komunikasi Universitas Tarumanagara
}

\begin{abstract}
This research was conducted to find out how self-identity was built and formed. By using concepts, self-identity consists of the construction of self-identity, the factors that influence identity, the process of forming self-identity. This research is a descriptive phenomenology study with a qualitative approach. The method used in collecting data is through in-depth interview techniques, non-participant observation, library studies, and online data search. The results of this study indicate that self-identity is built by the process of forming selfidentity due to the presence of figures who are models and levels of individual openness to various alternative identities. In addition, it was formed through digital media and conventional media such as Anime (Japanese cartoons), Manga (Japanese comics), and the surrounding environment.
\end{abstract}

Keywords: self-identity, cosplay, cosplayer, crossdress, character.

\begin{abstract}
Abstrak
Penelitian ini dilakukan untuk mengetahui bagaimana identitas diri dibangun dan dibentuk. Dengan menggunakan konsep, identitas diri yang terdiri dari konstruksi identitas diri, faktorfaktor yang mempengaruhi identitas, proses pembentukkan identias diri. Penelitian ini merupakan studi fenomenologi yang bersifat deskriptif dengan pendekatan kualitatif. Metode yang dilakukan dalam mengumpulkan data yakni dengan teknik wawancara mendalam, observasi non-partisipan, studi kepustakaan, dan penelusuran data online. Hasil dari penelitian ini menunjukkan bahwa identitas diri dibangun oleh proses pembentukan identitas diri yang dikarenakan adanya figur yang menjadi model dan tingkat keterbukaan individu terhadap berbagai alternatif identitas. Selain itu, terbentuk melalui media digital maupun media konvensional seperti Anime (kartun Jepang), Manga (komik Jepang), serta lingkungan disekitarnya.
\end{abstract}

Kata Kunci: identitas diri, cosplay, cosplayer, crossdress, tokoh.

\section{Pendahuluan}

Pada zaman era globalisasi seperti saat ini, masyarakat mampu mengakses segala informasi dan pengetahuan dengan sangat cepat dan praktis. Salah satunya ialah mampu memperoleh informasi mengenai suatu budaya yang terdapat di negara tertentu. Informasi mengenai budaya negara Jepang salah satunya yang dapat diakses dan diperoleh dengan baik oleh masyarakat Indonesia. Perubahan budaya dengan perkembangan zaman membuat definisi budaya populer menjadi semakin kompleks. Menurut Raymond William dalam Storey (2004) istilah populer memiliki empat makna, yakni: "banyak disukai orang", "jenis kerja rendahan", "karya yang dilakukan untuk menyenangkan orang", dan "budaya yang memang dibuat oleh orang untuk dirinya sendiri” (Adi, 2011). Kini, budaya populer yang berasal dari 
negara Jepang tersebut telah dapat diterima dengan baik oleh masyarakat khususnya masyarakat Indonesia. Salah satunya ialah festival Gelar Jepang Universitas Indonesia (GJUI). Festival ini merupakan acara rutin yang diadakan setiap tahun. Festival tersebut diselenggarakan sebagai salah satu bentuk usaha dalam memperkenalkan seni, budaya, edukasi, serta makanan khas negera Jepang (https://news.okezone.com/read/2016/08/15/65/1463659/kenali-indahnya-negeri-

sakura-di-gelar-jepang-ui, diakses diakses pada tanggal 2 Oktober 2018. Pukul 22.07 $\mathrm{pm})$.

Menurut observasi awal dari peneliti event budaya Jepang ditemukan lebih dari sepuluh crossdress cosplay ditengah event budaya Jepang tersebut selagi melakukan kegiatan Cosplay. Cosplay adalah istilah bahasa Inggris buatan Jepang (Wasei-Eigo) yang berasal dari gabungan kata "costume" (kostum) dan "play" (bermain). Cosplay merupakan kegiatan yang menirukan pakaian beserta aksesoris dan rias wajah. Cosplay sendiri merupakan istilah bagi orang yang memiliki hobi mengenakan kostum ala karakter seperti tokoh-tokoh dalam anime (kartun Jepang), manga (komik Jepang), manhwa, dongeng, permainan video, penyanyi dan musisi idola, dan film kartun. Pelakunya biasa disebut cosplayer (https://www.viva.co.id/vbuzz/283392arti-dan-sejarah-dari-cosplay-jepang, diakses pada tanggal 2 Oktober 2018, pukul $22.33 \mathrm{pm})$. Di Indonesia sendiri, awalnya cosplay tidak begitu dikenal oleh masyarakat di Indonesia. Menurut Rastati (2012) sebagai key informan, di Indonesia sendiri awalnya cosplay tidak begitu dikenal oleh masyarakat di Indonesia. Hingga awal tahun 1990 UI mulai menggelar festival Jepang seperti Gelar Jepang UI yang juga mengadakan cosplay.

Fenomena belakangan ini banyak bermunculan di luar komunitas-komunitas cosplayer. Bagi masyarakat awam, para pelaku cosplayer dianggap telah menghilangkan identitas dirinya. Mereka beranggapan bahwa cosplay merupakan suatu kegiatan yang hanya "menguras" banyak uang, tetapi tidak sedikit juga masyarakat yang mendukung kegiatan ini (https://www.antaranews.com/berita/394492/memuaskan-batin-lewat-cosplay, diakses 6 Oktober 2018, pukul 17.05)

Belakangan ini muncul fenomena menarik di antara para pelaku cosplayer. Cosplayer laki-laki dengan cosplay karakter perempuan maupun cosplayer perempuan dengan cosplay karakter laki-laki dalam karakter manga (komik Jepang), game, dan anime. Fenomena tersebut dapat dikatakan sebagai crossdresser cosplay. Identitas yang dibangun oleh seorang crossdress cosplayer Jepang merupakan keunikan tersendiri bagi mereka yang menjalankannya saat melakukan crossdress cosplay tersebut. Maka dari itu, menurut Chris Barker (2004) identitas itu masalah perbedaan dan kesamaan tentang aspek personal dan sosial. Disini ditekankan bahwa setiap orang memiliki keunikannya masing-masing dari dalam diri mereka.

Penelitian ini dilakukan agar dapat memberikan gambaran mengenai bagaimana pengakuan identitas para pelaku cosplayer yang melakukan Crossdresser.

\section{Metode Penelitian}

Metode yang digunakan oleh peneliti dalam melakukan penelitian ini adalah metode penelitian kualitatif. Menurut Denzin dan Lincoln (dalam Moleong, 2009), penelitian kualitatif adalah penelitian yang menggunakan latar alamiah, dengan maksud menafsirkan fenomena yang terjadi dan dilakukan dengan jalan melibatkan berbagai metode yang ada. Peneliti melakukan metode penelitian kualitatif agar 
mampu menjelaskan dan menafsirkan fenomena dengan berbagai macam metode yang akan digunakan. Biasanya dalam penelitian kualitatif, peneliti menggunakan metode wawancara, pengamatan dan pemanfaatan dokumen. Dengan teknik wawancara mendalam, observasi non-partisipan, studi kepustakaan, dan penelusuran data online. Pada penelitian ini, penulis memilih teknik in depth interview. Menurut Kriyantono (2012), wawancara mendalam adalah suatu cara mengumpulkan data atau informasi dengan cara langsung bertatap muka dengan informan agar mendapatkan data lengkap dan mendalam.

Penelitian ini ditujukkan kepada pelaku cosplay, terutama crossdress cosplay. Menurut Sugiyono (2012), penelitian kualitatif tidak menggunakan istilah populasi, tetapi oleh Spradley dinamakan "social situation" atau situasi sosial yang terdiri atas tiga elemen, yaitu tempat (place), pelaku (actor), dan aktivitas (activity) yang berinteraksi secara sinergis. Situasi sosial tersebut dapat dinyatakan sebagai objek penelitian yang ingin dipahami secara mendalam "apa yang terjadi" didalamnya.

Peneliti melakukan wawancara mendalam dan observasi terhadap enam informan crossdress cosplayer dan salah satunya merupakan key informan. Dalam melakukan wawancara mendalam, peneliti memberikan pertanyaan seputar identitas yang dibentuk dan dibangun oleh crossdress cosplayer. Setelah melakukan wawancara mendalam kepada crossdress cosplayer, peneliti melakukan wawancara kepada key informan untuk melakukan verifikasi. Selain itu, peneliti juga melakukan teknik pengolahan data dengan menggunakan reduksi data, penyajian data, dan menarik kesimpulan. Setelah melakukan teknik pengolahan data, peneliti melakukan teknik keabsahan data dengan triangulasi.

\section{Hasil Temuan dan Diskusi}

Peneliti melakukan penelitian terhadap para informan yang melakukan kegiatan crossdress cosplay Jepang. Pembentukan identitas crossdress cosplayer Jepang terbentuk karena adanya kontribusi dari perkembangan remaja, keluarga, dan individuasi dan connectednes. Saat para narasumber melakukan kegiatan cosplay biasa maupun crossdress cosplay, biasanya mereka menggunakan nama panggung agar dapat lebih mendalami karakter yang sedang mereka mainkan. Hal ini dilakukan agar mereka dapat membangun identitas diri mereka yang baru saat crossdress cosplay. Menurut Chris Barker (2004) konstruksi identitas diri adalah bangunan identitas diri, memperlihatkan siapa diri kita sebenarnya dan kesamaan kita dengan sejumlah orang dan apa yang membedakan kita dengan yang lainnya.

1. Identitas Sosial. Dari ketiga narasumber yang telah diwawancarai dapat terlihat bahwa mereka mulai melakukan kegiatan cosplay tersebut, dikarenakan mereka diajak oleh teman sebaya yang berada dalam kelompok bermainnya. Seperti yang diungkapkan oleh narasumber Ivan, Asyiva, serta Rena,

2. Identitas Diri. Narasumber laki-laki yang melakukan crossdress cosplay mengungkapkan bahwa mereka akan terus melakukan kegiatan ini dikarenakan mereka menganggap memiliki kemampuan yang mungkin tidak dimiliki oleh orangorang lainnya. Hal ini sejalan dengan ungkapan dari narasumber Ivan dan Reza.

Faktor-faktor yang mempengaruhi identitas menurut Erickson (dalam Nafi'ul, 2014) yakni: 1) Perkembangan Para Remaja, 2) Kontribusi keluarga, 3) Kontribusi individuasi dan connectedness. Proses pembentukkan identitas diri menurut Erickson (dalam Nafi'ul, 2014) adalah eksperimentasi kepribadian dan peran. Erikson yakin bahwa remaja akan mengalami sejumlah pilihan dan titik tertentu akan memasuki 
masa moratorium. Marcia (Santrock, 2003) mengungkapkan bahwa pembentukan diri diawali oleh munculnya ketertarikan (attachment), perkembangan suatu pemikiran mengenai diri dan pemikiran mengenai hidup dimasa tua. Berdasarkan landasan teori yang disebutkan, sejalan dengan temuan yang dilakukan oleh peneliti. Dari kelima narasumber yang telah diwawancarai mengungkapkan bahwa mereka memiliki ketertarikan dalam melakukan kegiatan cosplay dikarenakan kebudayaan populer Jepang melalui media merupakan salah satu faktor yang berkontribusi dalam proses pembentukkan identitas diri mereka sebagai crossdress cosplayer. 4) Ciri-ciri Pencapaian Identitas Diri menurut Erickson (dalam Nafi'ul, 2014) proses identitas diri sudah berlangsung sejak anak mengembangkan kebutuhan akan rasa percaya (trust), otonomi diri (autonomy), rasa mampu berinisiatif (initiative), dan rasa mampu menghasilkan sesuatu (industry) Sesuai pendapat yang dipaparkan oleh Erickson (dalam Nafi'ul, 2014), para narasumber yang memiliki hobi crossdress cosplay pun telah yakin atas keputusan yang diambil dalam melakukan hobi tersebut, terdapat batas dimana mereka sempat memikirkan untuk tidak melanjutkan atau berhenti melakukan hobi crossdress cosplay dikarenakan alasan yang beragam. Keempat komponen ini memberikan kontribusi kepada pembentukkan identitas diri. 5) Peranan Model Dalam Pembentukan Identitas Diri. Anak-anak yang mendekati usia dewasa tampak mengambil sesuatu di mana mereka ingin dilihat sebagai siapapun kecuali orangtua mereka. Mereka berhenti menghabiskan waktu bersama keluarga dan jika mungkin terlihat sejarang mungkin bersama orangtua. Anak-anak yang mendekati usia dewasa tampak mengambil sesuatu dimana mereka ingin dilihat sebagai siapapun kecuali orangtua mereka. Mereka berhenti menghabiskan waktu bersama keluarga dan jika mungkin terlihat sejarang mungkin bersama orangtua. Dari pernyataan tersebut, dapat disimpulkan bahwa para narasumber yang telah diwawancarai oleh peneliti, mereka lebih akan mencari role model dari film, anime (kartun Jepang), hingga idol yang mereka sukai untuk dijadikan panduan dalam kehidupan mereka.

Berdasarkan hasil temuan, maka peneliti akan membahas lebih dalam mengenai identitas diri para crossdress cosplay Jepang yang dibentuk dan dibangun yang terjadi pada diri crossdress cosplayer Jepang. Pada penelitian ini, peneliti berfokus pada perihal identitas diri yang berkaitan dengan identitas pribadi seseorang. Menurut Chris Barker (2004), identitas merupakan masalah perbedaan dan kesamaan tentang aspek personal dan sosial. Disini Barker menekankan bahwa setiap orang memiliki keunikannya masing-masing dari dalam diri mereka.

Pembentukkan identitas crossdress cosplayer Jepang terbentuk karena adanya kontribusi dari perkembangan remaja, keluarga, dan individuasi dan connectednes. Hal ini sejalan dengan pendapat yang diungkapkan oleh Ranny Rastati yakni saat para narasumber melakukan kegiatan cosplay biasa maupun crossdress cosplay, biasanya mereka menggunakan nama panggung agar dapat lebih mendalami karakter yang sedang mereka mainkan. Hal ini dilakukan agar mereka dapat membangun identitas diri mereka yang baru saat crossdress cosplay.

Berdasarkan penelitian pada crossdresser cosplayer Jepang, peneliti menemukan dari kelima narasumber bahwa mereka menunjukkan identitas dirinya sebagai crossdress cosplayer Jepang melalui pakaian serta make-up yang mereka gunakan saat memerankan tokoh tertentu. Komunikasi diperlukan dalam setiap hubungan manusia. Dengan komunikasi, manusia mampu menyampaikan pesan. Baik itu, pesan verbal maupun non-verbal. Komunikasi tidak hanya terjadi di satu tempat saja. Melainkan, terjadi pada kapan saja, dan oleh siapa saja. Seperti 
komunikasi non-verbal yang disampaikan oleh para crossdress cosplayer Jepang. Saat mereka menggunakan pakaian tokoh yang mereka sukai serta mengungkapkan ekspresi mereka.

Identitas diri dapat terbentuk bahwa setiap orang memiliki keunikan masingmasing dari dalam diri mereka. Seperti para crossdresser cosplayer Jepang melakukan kegiatan tersebut. Menurut mereka kegiatan tersebut merupakan kegiatan yang unik karena mampu mengasah kreativitas dan keahlian mereka dalam melakukan make-up. Dengan demikian, sesuai dengan teori yang dikemukakan oleh Chris Barker yaitu identitas itu masalah perbedaan dan kesamaan tentang aspek personal dan sosial. Di sini Barker menekankan bahwa setiap orang memiliki keunikannya masing-masing dari dalam diri mereka. Berdasarkan penelitian pada crossdresser cosplayer Jepang, peneliti menemukan dari kelima narasumber bahwa mereka menunjukkan identitas dirinya sebagai crossdress cosplayer Jepang melalui pakaian serta make-up yang mereka gunakan saat memerankan tokoh tertentu.

Dalam pembentukan identitas diri, terdapat beberapa faktor identitas yakni identitas sosial dan identitas diri. Identitas sosial terbentuk akibat dari keanggotaan seseorang itu dalam suatu kelompok kebudayaan. Tipe kelompok itu antara lain, umur, gender, kerja, agama, kelas sosial, dan tempat. Begitu pula dari para pelaku crossdress cosplayer Jepang. Seperti Ivan yang awalnya hanya mengikuti kegiatan cosplay Jepang saat ia bersama teman yang sudah terlebih dahulu melakukan cosplay. Konsumsi media pun juga turut ikut berperan dalam pembentukkan identitas sosial dari para pelaku crossdress cosplayer Jepang yakni seperti anime (kartun Jepang) dan manga (komik Jepang). Sedangkan, identitas diri didasarkan pada keunikan karakteristik pribadi seseorang. Seperti karakter, kemampuan, bakat, dan pilihan. Dan lain sebagainya. Begitu pula dengan para pelaku crossdress cosplayer Jepang seperti Ivan dan Reza. Ivan mampu merubah dirinya menjadi tokoh perempuan dari sebuah anime (kartun Jepang) dengan menggunakan make-up yang selama ini ia latih. Sedangkan, Reza yang mempunyai bakat dalam menirukan suara perempuan saat melakukan kegiatan crossdress cosplayer Jepang dan melakukan make-up terhadap dirinya.

Kemudian, dalam pembentukkan identitas diri terhadap para crossdress cosplayer Jepang terdapat beberapa faktor yang mampu memberikan kontribusi terhadap diri para crossdress cosplayer Jepang. Diantaranya perkembangan para remaja, kontribusi keluarga, serta kontribusi individuasi dan connectednes. Para pelaku crossdress cosplayer Jepang mayoritas merupakan para remaja. Pada masa ini, mereka ingin mencoba hal yang baru, yang unik, dan tidak biasa. Contohnya kegiatan crossdress cosplay Jepang merupakan kegiatan yang biasa dilakukan kelima narasumber seperti Ivan, Asyiva, Shabrina, Reza, dan Nadira. Dengan melakukan kegiatan crossdress cosplay Jepang mereka mampu memunculkan kemampuan dalam melakukan crossdress cosplay dan kepercayaan diri mereka. Selain adanya kontribusi dari perkembangan remaja, faktor keluarga juga memberikan kontribusi yang besar dalam pembentukkan identitas diri dari para crossdress cosplayer Jepang. Seperti yang dirasakan oleh narasumber Ivan dan Shabrina. Keluarga dari Ivan awalnya tidak mendukung kegiatan crossdress cosplay Jepang, namun Ivan terus memberikan pengertian bahwa kegiatan crossdress cosplay Jepang tidaklah buruk sebab kegiatan ini hanyalah hobi belaka. Sebaliknya keluarga Shabrina terus memberikan dukungan terhadap kegiatan crossdress cosplay Jepang tersebut dikarenakan kegiatan tersebut lebih menunjukkan kesopanan narasumber Shabrina dalam hal berpakaian. 
Lalu faktor yang ikut berperan dalam berkontribusi pembentukan identitas diri yakni adanya atmosfir hubungan keluarga akan membantu pembentukan identitas diri remaja dengan cara merangsang individualitas dan ketertarikkan satu sama lain (connectedness). Individualitas menyangkut kemampuan individu dalam mengemukakan pendapatnya, perasaan bahwa dirinya berbeda dengan orang lain atau anggota keluarga yang lain. Sedangkan connectedness berkaitan dengan kebersamaan sensitivitas, keterbukaan terhadap kritikan.

Begitu pula narasumber Shabrina, pada awalnya keluarga menganggap bahwa kegiatan crossdress cosplay Jepang yang dilakukan merupakan sesuatu yang lucu dan seru. Sedangkan bagi narasumber Reza, memiliki connectedness bersama komunitas crossdress cosplay Jepang di mana dia bergabung ke dalam komunitas tersebut. Tetapi, selama mengenakan crossdress tidak sedikit menerima kritikan berupa gunjingan yang berasal dari lingkungan sekitar terutama saat berada dalam lingkungan event Jepang.

\section{Simpulan}

Dalam pengungkapan identitas diri, para crossdress cosplayer Jepang didasari oleh adanya kemampuan, karakter, dan bakat dari setiap informan. Adanya komunikasi nonverbal artifaktual melalui pakaian serta make-up yang mereka kenakan selama event Jepang. Selain itu, adanya identitas sosial juga ikut berkontribusi dalam membentuk identitas diri para crossdress cosplayer Jepang. Seperti adanya kontribusi pertemanan dan konsumsi media Anime (kartun Jepang) dan Manga (komik Jepang).

\section{Ucapan Terima Kasih}

Atas terselesaikannya penelitian ini, peneliti mengucapkan terima kasih kepada orang tua yang memberikan dukungan dan doa, Bapak Yugih Setyanto, S.Sos., M.Si., selaku pembimbing utama dan Ibu Septia Winduwati, S,Sos., M.Si., selaku copembimbing skripsi, serta informan yang membantu peneliti untuk bersedia diwawancarai.

\section{Daftar Pustaka}

Barker, C. (2004). Cultural Studies, Teori dan Praktik. Yogyakarta: Kreasi Wacana Erickson, Erick, H. (1989). Identitas dan Siklus Hidup Manusia. Bunga Rampai Penerjemah: Agus Cremers. Jakarta: PT. Gramedia

Ikhwan, Nafi'ul. (2014). Identitas Diri Reggae Mania di Gresik. Diunduh pada tanggal 22 Agustus 2018)

Kriyantono, Rachmat. (2012). Teknik Praktis Riset Komunikasi: disertai contoh paktis riset media Public Relations, Advertising, Komunikasi Organisasi, Komunikasi Pemasaran. Jakarta: KencanaPredana Media Group.

Marcia, James E. (1980). Ego Identity: A Handbook of Psychosocial Research. New York: Springer-Verlag

Moleong. Lexy J. (2008). Metodelogi Penelitian Kualitatif. Bandung: PT. Remaja Rosdakarya.

Moleong. Lexy J. (2009). Metodelogi Penelitian Kualitatif. Bandung: PT. Remaja Rosdakarya. 
Fasa Bikati Sabka, Yugih Setyanto, Septia Winduwati: Pengungkapan Identitas Diri Melalui Komunikasi Non Verbal Artifaktual Pada Komunitas Crossdress Cosplay Jepang

Mulyana, Deddy. (2008). Human Communication: Prinsip-prinsip Dasar. Bandung: PT Remaja Rosdakarya

Sugiyono. (2011). Metodologi Penelitian Pendidikan: Pendekatan Kuantitatif, Kualitatif, dan R\&D. Bandung: CV. Alfabeta 